\title{
INVESTIGATION OF HYDROABRASIVE RESISTANCE OF TITANIUM ALLOY VT6S USED FOR CENTRIFUGAL COMPRESSOR WHEELS
}

\author{
M.A. KOVALEV ${ }^{1}$, A. D. DAVYDOV ${ }^{2}$, O.V. SCHVETSOV ${ }^{3}$, D.V. LYASHENKO ${ }^{4}$ \& E.N. POMORCEV ${ }^{5}$ \\ 1,2,3,4 National Technology Initiative Center for Advanced Manufacturing Technologies based on the Institute of Advanced \\ Manufacturing Technologies of Peter the Great St. Petersburg Polytechnic University Polytechnicheskaya, 29,
} St.Petersburg, 195251, Russia

${ }^{2}$ JSC "NIIturbokompressor im. V.B. Shneppa"

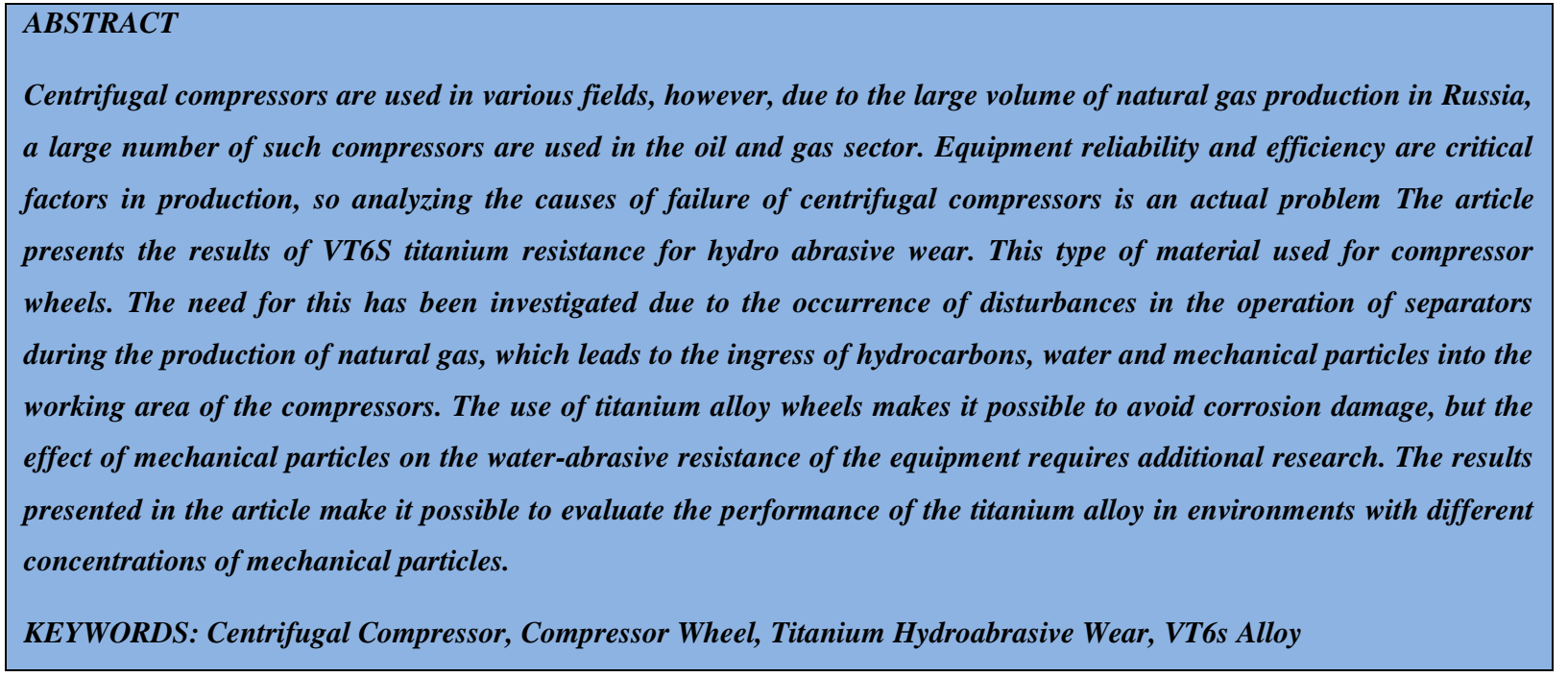

Received: Jun 09, 2020; Accepted: Jun 29, 2020; Published: Sep 28, 2020; Paper Id.: IJMPERDJUN20201448

\section{INTRODUCTION}

Corrosion in the oil and gas industry is one of the main causes of equipment failure $[1,2,3,4]$. In addition to the developed pipeline network, the energy complex will use various equipment involved in the extraction and processing and transportation of raw materials. One example of such equipment is centrifugal compressor units used in the extraction and pumping of natural gas. For example, the number of large compressors used in the production structures of «Gazprom» is more than four thousand units [4]. The trouble-free operation of centrifugal compressors directly affects the financial performance of mining companies therefore, special attention is paid to the reliability of compressor elements [5].

One of the options for the failure of a compressor unit is the destruction of the wheels. Compressor wheels can be made of stainless steels, such as AISI 301, 12CrMnMoWNb, 10CrMn2SiMo, as well as titanium alloys [6]. The choice of material depends on the requirements for strength characteristics and operating conditions. There are various cases of compressor wheel damage, the causes of which are formed at the production stage or directly during operation [7]. Typically, the fracture scenario includes the initiation and development of fatigue cracks under the action of alternating loads and vibrations [8]. One of the causes of cracks in the wheel body may be the presence of a corrosive environment, as well as the presence of mechanical particles in the pumped gas [9]. Under the condition of poor-quality purification of the produced gas, hydrocarbons, water and mechanical particles enter the 
compressor working space. The combined effect of the components described above, together with hydrogen sulfide and carbon dioxide, can lead to corrosion damage to the compressor wheels, for example, sulfide stress corrosion cracking [10].

In the presence of high concentrations of hydrogen sulfide in the composition of the centrifugal compressor, wheels made of titanium alloys are used. A large number of works have been devoted to the study of the tendency of steels to sulfide stress corrosion cracking, based on which it can be concluded that titanium alloys are least susceptible to this type of fracture $[11,12,13]$.

Compressor wheels made of titanium alloy can successfully operate in environments with high $\mathrm{H} 2 \mathrm{~S}$ content, as they are not prone to hydrogen sulfide stress corrosion cracking. The disadvantage of titanium wheels is the increased hydroabrasive wear resistance compared to steel products in the presence of mechanical impurities in the produced gas [14, $15,16]$

The article presents the results of a study of the hydroabrasive resistance of titanium VT6S grade. The studies were carried out as part of the work on the analysis of the causes of destruction of the titanium wheel of a centrifugal compressor operating in the field during natural gas production. In the process of pumping the produced gas, hydrocarbons, water and mechanical impurities entered the working zone of the compressor. This was due to the unsatisfactory performance of the separator. Figure 1 shows the morphology of the damaged wheel surface.

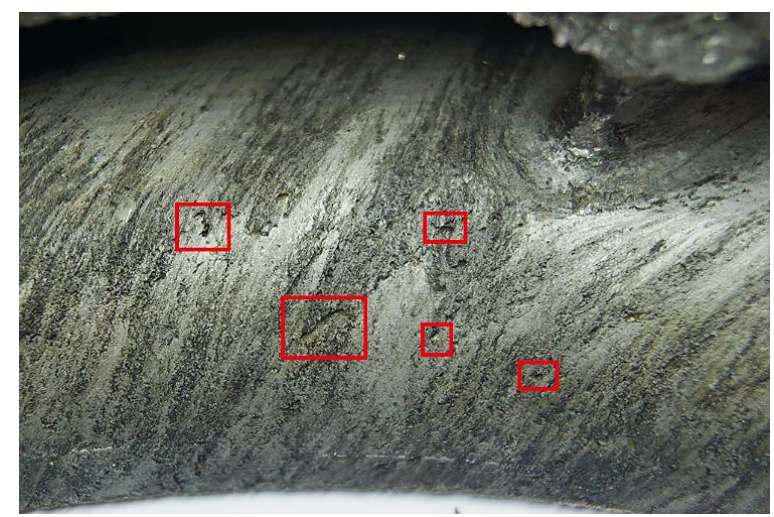

Figure 1: Surface of the Compressor Wheel.

The compressor operating time was 5000 hours, while the design documentation indicated the maximum concentration of mechanical particles $-0.05 \%$ by weight. In order to show the actual excess of the concentration of mechanical particles during operation, as well as to evaluate their effect on the titanium alloy VT6S, tests for hydroabrasive wear were carried out.

The aim of the work is to assess the effect of the concentration of mechanical particles on the water-abrasive resistance of VT6S titanium and to calculate the theoretical losses in compliance with the requirements of the design documentation.

\section{EXPERIMENTAL METHODS}


The study of waterjet resistance is, as a rule, a non-trivial task due to the lack of standard techniques and a large number of variable parameters. For this reason, research laboratories develop and create unique test facilities that allow evaluating the effect of flow with mechanical particles on various materials.

The assessment of the hydroabrasive wear of the VT6S alloy was carried out on a setup that allows simulating wear under the influence of an environment with a given concentration of mechanical particles (figure 2). The installation includes a working container, which houses the nozzle and the sample suspension. The nozzle is located above the center of the sample with the ability to adjust the distance to it. The working solution is supplied by a pump through a closed system, which ensures constant circulation and distribution of mechanical particles. The solution consists of distilled water and quartz sand with a fraction of 0.4-0.8 mm acting as mechanical impurities.

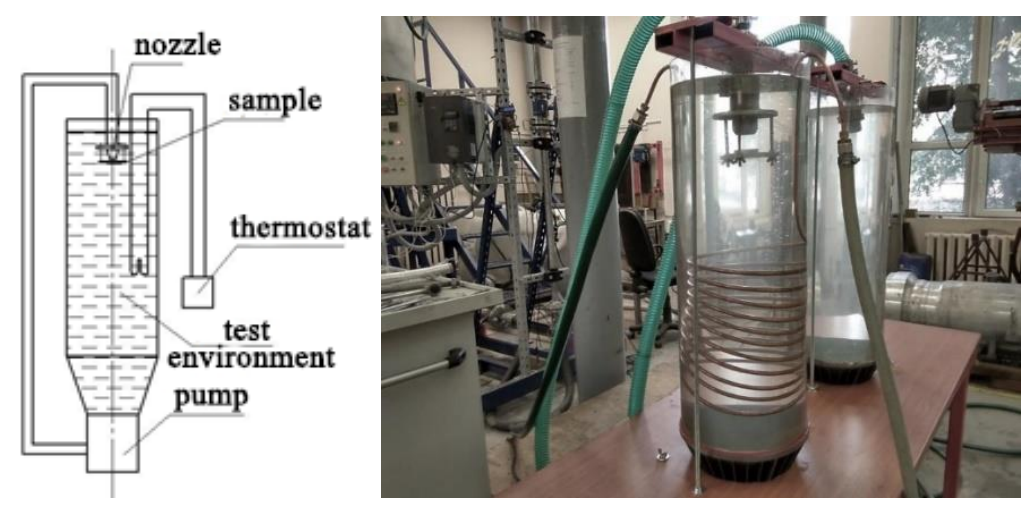

Figure 2: Installation for Hydroabrasive Testing.

The tests were carried out at concentrations of mechanical impurities of $0.5,1$ and 1.5 wt $\%$. The design documentation for a centrifugal compressor indicated that the concentration of mechanical particles should not exceed 0.05 $\mathrm{wt} \%$.

The concentrations were selected in order to establish the dependence of the increase in the wear rate on the concentration of mechanical impurities, as well as to be able to predict the wear rate at other percentages of mechanical particles. The tests were carried out for 7 and 21 hours, after which the weight loss was measured to assess the effect of hydroabrasive wear.

\section{RESULTS}

In order to assess the effect of hydroabrasive wear after testing, the weight loss of the samples was estimated, and the rate of weight loss was also determined. The test results are shown in Table 1.

Table 1: The Results of Hydroabrasive Tests

\begin{tabular}{|c|c|c|c|c|}
\hline \multirow{2}{*}{ Concentration of Mechanical Particles, \% } & \multicolumn{2}{|c|}{ Weight Loss, $\mathbf{g}$} & \multicolumn{2}{c|}{ Weight Loss Rate, g / h } \\
\cline { 2 - 5 } & After 7 Hours & After 21 Hours & After 7 Hours & After 21 Hours \\
\hline 0,5 & 0,03 & 0,09 & 0,0049 & 0,0046 \\
\hline 1 & 0,07 & 0,16 & 0,010 & 0,007 \\
\hline 1,5 & 0,10 & 0,26 & 0,014 & 0,012 \\
\hline
\end{tabular}

A sample after testing for 21 hours with concentration of mechanical impurities of $1.5 \%$ is shown in Figure 3. 


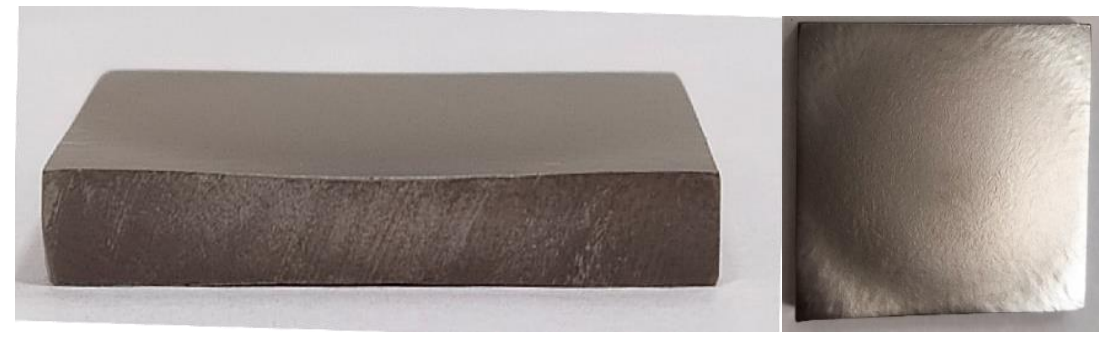

Figure 3: Sample After Hydroabrasive Tests for 21 Hours.

Figure 4 shows a graph of the change in the wear rate depending on the concentration of mechanical impurities.

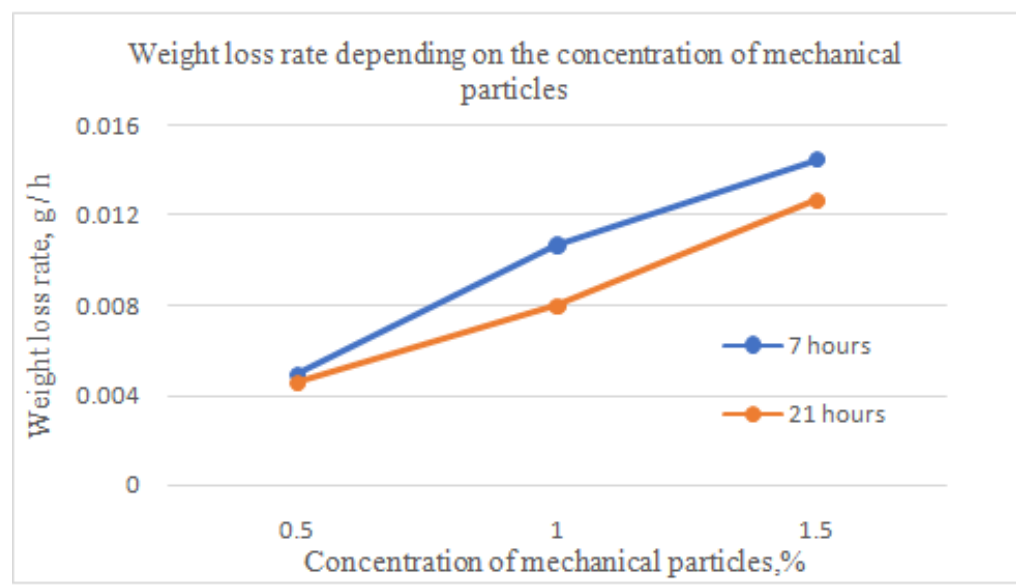

Figure 4: Change in the Rate of Weight Loss Depending on the Concentration of Mechanical Particles.

Figure 5 shows a graph of weight loss versus the concentration of mechanical particles.

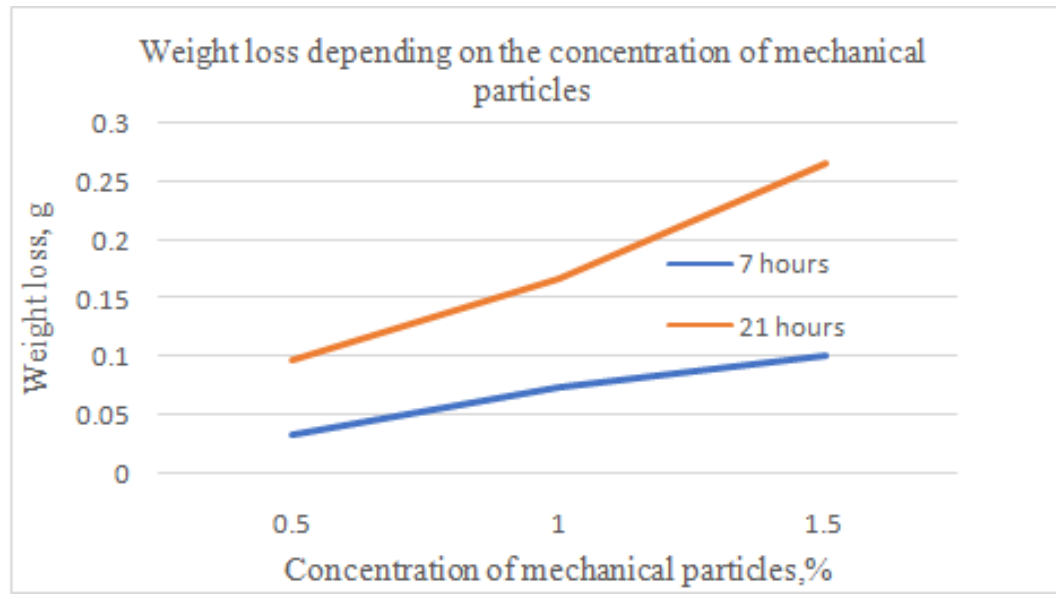

Figure 5: Change in Weight Loss Depending on the Concentration of Mechanical Particles.

According to the results of hydroabrasive tests, an increase in the weight loss of samples was noted with an increase in the concentration of mechanical impurities. The amount of wear when tested with an impurity concentration of $1.5 \%$ of the mass. increased threefold compared with tests at a concentration of $0.5 \%$ of the mass. The weight loss rate during the 7-hour test was on average $0.002 \mathrm{~g} / \mathrm{h}$ higher than during the 21 -hour test. 


\section{DISCUSSION}

Based on the data presented in the design documentation, the content of mechanical particles during operation should have been at a level of no more than $0.05 \%$ by weight. According to the study, the relationship between the concentration of mechanical particles and the amount of wear is linear, therefore it can be assumed that at a concentration of $0.05 \%$ of the mass. The wear rate would be $\approx 0.002 \mathrm{~g} / \mathrm{h}$. According to the data presented, with an operating time of 5000 hours, the losses would be approximately $10 \mathrm{~g}$ of metal. However, on the compressor wheel obtained for the study, lesions up to 1.5 $\mathrm{mm}$ deep and local thinning were present, which exceeds the weight loss obtained in laboratory studies. Presumably, this indicates an excess of the concentration of mechanical particles during operation, and therefore this could serve as one of the reasons for equipment failure.

\section{CONCLUSIONS}

The studies and tests carried out have shown the dependence of the degree of hydroabrasive wear of the VT6S titanium alloy on the concentration of mechanical particles. The amount of wear when tested with an impurity concentration of $1.5 \%$ of the mass. Increased threefold compared with tests at a concentration of $0.5 \%$ of the mass. Based on the data obtained, the theoretical wear rate of the compressor wheel was calculated. The estimated wear rate does not correspond to the actual losses, which indicates an excess of the concentration of mechanical particles during operation. To prevent such destruction in the future, it is necessary that all the elements and mechanisms involved in the production process meet the requirements of the design documentation. In the case considered, the probable cause of hydroabrasive wear was insufficient filtration of the incoming gas.

\section{REFERENCES}

1. Corrosion testing of experimental steels for oilfield pipelines, Alkhimenko A., E3S Web of Conferences 121, 01001 (2019)

2. Comparative Analysis of Corrosion-Resistant Alloys Inconel 718 and ÉP718A. A. Khar'kov, A. V. Shakhmatov, E. L. Gyulikhandanov \& E. L. Alekseeva Chemical and Petroleum Engineering volume 54, pages771-778(2019)

3. Papavinasam, Sankara. Corrosion control in the oil and gas industry. Elsevier, 2013.

4. Akhiyarov, R.G., Laptev, A.B., Movenko, D.A., Belova, N.A. The study of the ultralow corrosion resistance of tube steel for heat exchange equipment in oil refining. Neftyanoe Khozyaystvo - Oil Industry. (1), c. 118-121 (2016)

5. Galerkin, U. B. "Turbocompressors. Workflow, calculation and design of the flow path." M .: KHT (2010)

6. Antipin N.A., Getsov L.B., Gnedenkov E.V.., Mozhaiskaya N.V., Rybnikov A.I., Semenov A.S. Durability and crack resistance of the wheels of centrifugal compressors, Gas industry (11), 120-120 (2017)

7. Farrahi G. H. et al. Failure analysis of a gas turbine compressor //Engineering Failure Analysis. - 2011. - T. 18. - №. 1. - C. 474-484.

8. Hou J., Wicks B. J., Antoniou R. A. An investigation of fatigue failures of turbine blades in a gas turbine engine by mechanical analysis //Engineering Failure Analysis. - 2002. - T. 9. - №. 2. - C. 201-211.

9. Fantechi F., Innocenti M. Chloride stress corrosion cracking of precipitation hardening SS impellers in centrifugal compressor. Laboratory investigations and corrective actions //Engineering Failure Analysis. - 2001. - T. 8. - №. 5. - C. 477492. 
10. Sun J. et al. Review on stress corrosion and corrosion fatigue failure of centrifugal compressor impeller //Chinese Journal of Mechanical Engineering. - 2015. - T. 28. - №. 2. -217-225.

11. Ueda, M., et al. "Corrosion behavior of titanium alloys in a sulfur-containing H2S-CO2-Cl- environment." Corrosion 48.1 (1992): 79-88.

12. Kane, R. D., Seth Craig, and A. Venkatesh. "Titanium alloys for oil and gas service: A review." CORROSION 2009. NACE International, 2009.

13. Raja, V. S., and Tetsuo Shoji, eds. Stress corrosion cracking: theory and practice. Elsevier, 2011.

14. Suchanek J. et al. Erosive and hydroabrasive resistance of hardfacing materials //Wear. - 1999. - T. 233. - C. 229-236.

15. Several erosion test results of means of sand control, Alkhimenko A., Shaposhnikov N., Shemyakinsky B., Tsvetkov A., E3S Web of Conferences 121, 03005 (2019)

16. Bermúdez M. D. et al. Erosion-corrosion of stainless steels, titanium, tantalum and zirconium //Wear. - 2005. - T. 258. - №. 1-4. - C. 693-700. 